\title{
New Insights into Osteogenic and Chondrogenic Differentiation of Human Bone Marrow Mesenchymal Stem Cells and Their Potential Clinical Applications for Bone Regeneration in Pediatric Orthopaedics
}

\author{
Nicola Giuliani, ${ }^{1}$ Gina Lisignoli, ${ }^{2}$ Marina Magnani, ${ }^{3}$ Costantina Racano, ${ }^{3}$ \\ Marina Bolzoni, ${ }^{1}$ Benedetta Dalla Palma, ${ }^{1}$ Angelica Spolzino, ${ }^{1}$ Cristina Manferdini, ${ }^{2}$ \\ Caterina Abati, ${ }^{3}$ Denise Toscani, ${ }^{1}$ Andrea Facchini, ${ }^{2}$ and Franco Aversa ${ }^{1}$ \\ ${ }^{1}$ Hematology, Department of Clinical and Experimental Medicine, University of Parma, Via Gramsci 14, 43126 Parma, Italy \\ ${ }^{2}$ SC Laboratorio di Immunoreumatologia e Rigenerazione Tissutale e Laboratorio RAMSES, Rizzoli Orthopaedic Institute, \\ Via di Barbiano 1/10, 40136 Bologna, Italy \\ ${ }^{3}$ Paediatric Orthopaedics and Traumatology, Rizzoli Orthopaedic Institute, Via GC Pupilli 1, 40136 Bologna, Italy
}

Correspondence should be addressed to Nicola Giuliani; nicola.giuliani@unipr.it

Received 29 March 2013; Accepted 8 May 2013

Academic Editor: Paul T. Sharpe

Copyright (C) 2013 Nicola Giuliani et al. This is an open access article distributed under the Creative Commons Attribution License, which permits unrestricted use, distribution, and reproduction in any medium, provided the original work is properly cited.

Human mesenchymal stem cells (hMSCs) are pluripotent adult stem cells capable of being differentiated into osteoblasts, adipocytes, and chondrocytes. The osteogenic differentiation of hMSCs is regulated either by systemic hormones or by local growth factors able to induce specific intracellular signal pathways that modify the expression and activity of several transcription factors. Runt-related transcription factor 2 (Runx2) and Wnt signaling-related molecules are the major factors critically involved in the osteogenic differentiation process by hMSCs, and SRY-related high-mobility-group (HMG) box transcription factor 9 (SOX9) is involved in the chondrogenic one. hMSCs have generated a great interest in the field of regenerative medicine, particularly in bone regeneration. In this paper, we focused our attention on the molecular mechanisms involved in osteogenic and chondrogenic differentiation of hMSC, and the potential clinical use of hMSCs in osteoarticular pediatric disease characterized by fracture nonunion and pseudarthrosis.

\section{Introduction}

Human mesenchymal stem cells (hMSCs) are pluripotent adult stem cells that can differentiate into different cell types of mesodermic origin, such as osteoblasts, adipocytes, and chondrocytes, as well as into other nonmesodermic cells $[1,2]$. MSCs were first discovered by Friedenstein in 1968 as adherent fibroblast-like cells with multipotent differentiation capacities showing that clonal populations belonging to the colony forming unit-fibroblastoids (CFU-Fs) give rise to bone, cartilage, and hematopoietic supportive cells in vivo $[1,2]$. MSCs have been originally isolated from bone marrow (BM); however, recently other tissues, such as adipose tissue, skeletal muscle, tendon, and trabecular bone, have been identified as potential sources of MSCs [1,2]. Interestingly, the capacity of vascular pericytes, also known as mural cells that surround endothelial cells and express MSC stem cell markers, has been recently demonstrated in multiple human organs $[3,4]$. These cells sustain long-term culture during which they express markers of mesenchymal stem cells and exhibit osteogenic, chondrogenic, and adipogenic potentials $[3,4]$, thus, supporting the hypothesis of a common perivascular origin of hMSC and postulating the existence of a ubiquitous reserve of multilineage progenitor cells in perivascular cells.

hMSCs were generally defined based on their capacity to self-renew and on the phenotype of their culture amplified progeny because of the lack of a specific and stable cell marker 
expressed by these cells both in vivo and in vitro. The International Society of Cellular Therapy (ISCT) proposed the minimal criteria for defining MSCs as follows: (i) adherence to plastic under standard tissue conditions, (ii) the expression of cell surface markers such as CD73, CD90, and CD105 and the lack of expression of CD34, CD45, CD14 or CD11b, CD79 or CD19, and HLA-DR, and (iii) the capacity to differentiate into osteoblasts, adipocytes, and chondroblasts [5]. However, in the last years, other markers have been associated with MSCs such as Stro-1, CD271, vascular cell adhesion molecule (VCAM)-1, and CD146 [6, 7]. Stro-1 is described to be highly specific for BM CFU-F. The function of Stro-1 on MSCs remains unknown, and its expression is downregulated during in vitro culture. Stro- $1^{+}$-expanded MSCs were reported to have a better homing capacity, compared to expanded Stro- $1^{-}$ MSCs, suggesting their potential role in MSCs migration and attachment to extracellular matrix $[6,7]$. Similarly, CD271 was found in isolated MSCs but down-regulated in culture. CD271 expression could be considered as an early marker of osteogenic capacity although its function remains unknown $[6,7]$. Recently, CD271 has been reported to define a subset of MSCs with immunosuppressive and lymphohematopoietic engraftment-promoting properties [6, 7]. Moreover, CD146 expression on MSCs has been associated with pericyte topography. Recently, it has been shown that CD146 expression on MSCs, positive for CD271, correlates with their in situ localization $[6,7]$.

The rationale for the use of MSCs in regenerative medicine is based on the different properties of these cells: (i) ability to migrate to the site of injury, (ii) the potential to differentiate in various mesenchymal tissues and, at least in vitro, into different cell lineages, (iii) the ability to release factors that influence cell survival and proliferation, and (iv) the modulation of immune response and inflammation. Beyond their multipotency, the capacity of MSCs to release trophic, anti-inflammatory, and immunomodulatory factors that may limit tissue injury and favor recovery seems to be critical in the proregenerative role of these cells $[1,8]$. In fact, several data indicate that MSCs can provide a local microenvironment that supports tissue regeneration such as angiogenesis and osteogenesis through the secretion of several cytokines including epidermal growth factor (HBEGF), basic fibroblast growth factor (bFGF), platelet-derived growth factor-B chain (PDGF-BB), vascular endothelial growth factor (VEGF), keratinocyte growth factor (KGF), and angiopoietins [9]. All these factors are well known to enhance tissue repair in vivo [9]. On the basis of this evidence, hMSCs have generated a great interest in the field of regenerative medicine, particularly in regeneration of bone and cartilage tissues $[1,8]$.

Because the low frequency of MSCs and MSC progenitors in the human BM and other tissues, the in vivo use of MSCs may require ex vivo expansion to achieve numbers of cells necessary for their clinical applications. Both ex vivo expanded and nonexpanded MSCs have been used for bone regeneration [10]. Differences in isolation methods and culture conditions may affect cell yield and the phenotype of the expanded MSCs cells such as reported for the downregulation of STRO-1 and CD271 [6, 7]. The European Group for Blood and Marrow Transplantation (EBMT) has defined a common MSC expansion protocol based on the use of prescreened $10 \%$ fetal calf serum (FCS) [11]. Nevertheless, as known, FCS could be theoretically responsible for the transmission of different infections (i.e., zoonoses) or cause immunization in the host recipients. For this reason, serumfree conditions have been investigated as well as the use of both autologous and allogeneic serums [10]. It has been reported that autologous serum was superior in terms of capacity of expansion of MSCs as compared to both allogenic serum and FCS [10]. Recently, platelet lysate has been demonstrated to be a useful substitute for FCS in MSC expansion [10].

Cultures of MSCs show heterogeneity, differential growth rate, and developmental potentials exhibited by individually expanded MSC clones. As a consequence, researchers are actively attempting to determine the genotypic and proteomic profiles of long-lived MSC clones in order to elucidate the mechanisms that regulate and maintain primitive MSC populations in expanded cells. Little is known regarding the proportion of expanded MSCs that remain as multipotential stem cells used in the cell therapies. Moreover, the efficacy of the MSCs in tissue regeneration largely depends on their homing capacity and the microenvironment that are critical in limiting or expanding in vivo the differentiation capacity of these cells [12].

In the past few years, the molecular mechanisms involved in the differentiation process of hMSCs have been elucidated, and the transcription factors involved in these processes identified that (Figure 1) these new acquisitions could improve our future expansion strategies and clinical use of MSCs. In this paper, we focus our attention on the molecular mechanisms involved in osteogenic and chondrogenic differentiation of hMSC, and the potential clinical use of hMSCs in osteoarticular pediatric disease characterized by fracture nonunion and pseudarthrosis.

\section{Osteogenic Differentiation of Bone Marrow hMSCs}

The osteogenic differentiation of BM hMSCs is regulated either by systemic hormones, such as parathyroid hormone (PTH), estrogens, and glucocorticoids, or by local growth factors, including the bone morphogenetic protein (BMP) family, transforming growth factor-beta (TGF- $\beta$ ), and fibroblast growth factor-2 (FGF-2) [13]. These factors activate specific intracellular signal pathways that modify the expression and activity of several transcription factors in hMSCs, which result in osteoblastic differentiation rather than chondrocytic, adipocytic, or myogenic ones [13] (Figure 1).

Runt-related transcription factor 2 (Runx2), also named Cbfal or AML3, is the major transcription factor regulating osteoblast commitment and osteogenic differentiation of MSCs $[13,14]$. Studies on mice lacking Runx2 indicated that the expression of Runx2 is critical for MSC differentiation toward the osteoblast lineage. Runx2-deficient $\left(\right.$ Runx $^{-/-}$) mice completely lack osteoblasts and bone formation, demonstrating a pivotal role for this factor in 


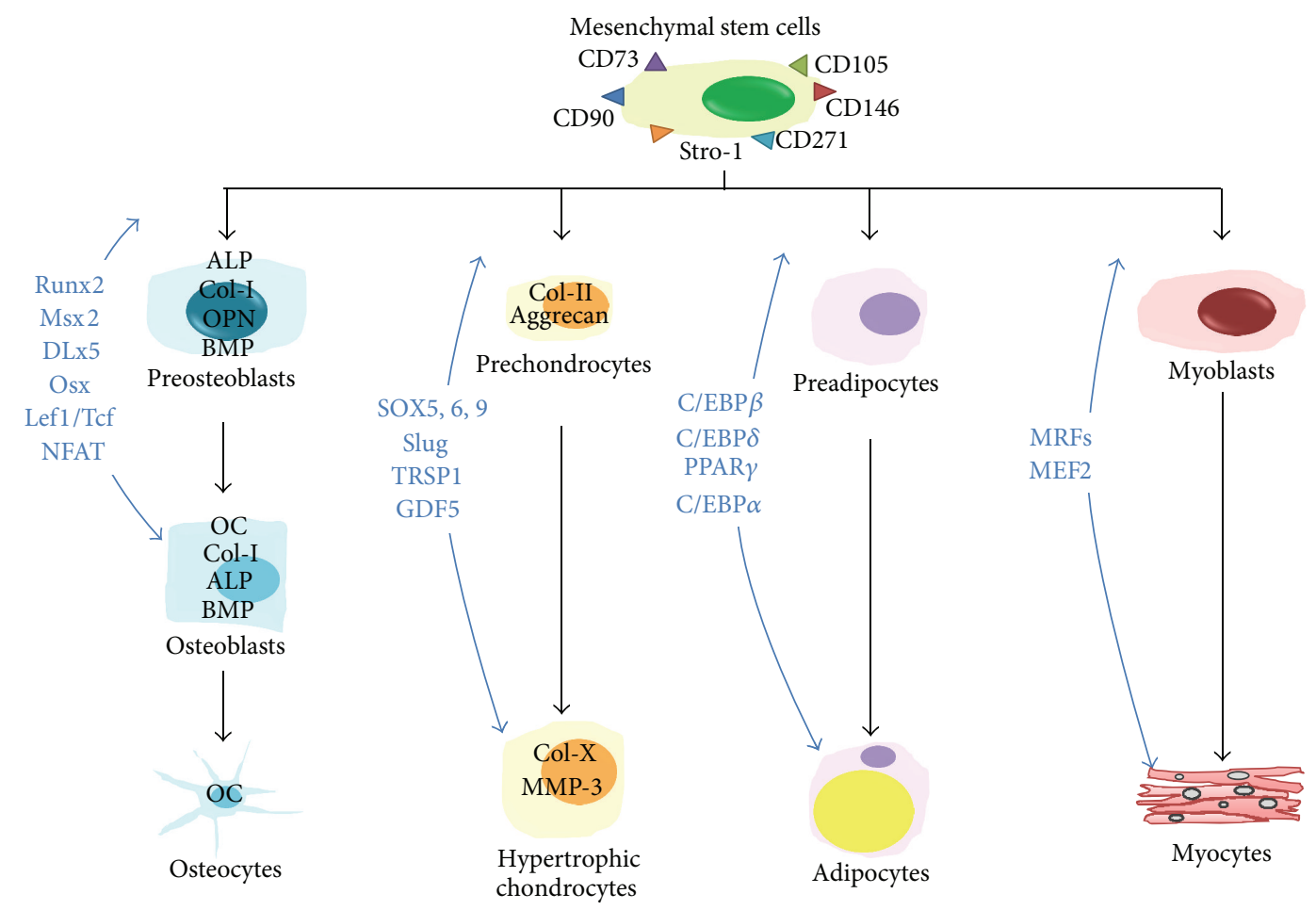

FIGURE 1: Multipotent differentiation of BM hMSCs. The commitment and differentiation of hMSCs towards osteogenic, chondrogenic, adipogenic, or myogenic lineage are regulated by specific transcription factors (indicated in blue). ALP, alkaline phosphatase; Col-I, type I collagen; OPN, osteopontin; BMP, bone matrix protein; OC, osteocalcin; Col-II, type II collagen; Col-X, type X collagen; MMP-3, matrix metalloproteinase-3.

osteoblastogenesis $[13,14]$. However, Runx2 overexpression also impairs bone formation in mice [15], indicating that its effect is dependent on the stage of osteoblast differentiation. Runx2-overexpressing mice also show enhanced bone resorption, possibly through increased expression of the osteoclast stimulating factor receptor activator of nuclear factor $\kappa \mathrm{B}$ ligand (RANKL) by osteoprogenitor cells [16]. Activation of Runx2 in human BM MSCs induces expression of the osteoblast-related markers collagen I, alkaline phosphatase, and osteocalcin during the early stages of osteoblast maturation [16, 17]. Both expression and activity of Runx2 are tightly regulated by other transcription factors as well as protein-DNA or protein-protein interactions. Runx2 itself is regulated by phosphorylation of the extracellular signalregulated kinase $(\mathrm{ERK}) / \mathrm{mitogen}$-activated protein kinase (MAPK) pathway [18]. Hey-1, Hoxa2, Stat1, and Sox9 interact with Runx2 and inhibit its expression and/or transcriptional activity and thus are negative regulators of osteoblast differentiation. Runx2 activity is also positively regulated by transcription factors such as TAZ, Hoxa10, or BAPX-1 [13, 14]. Moreover, multiple signaling pathways converge to interact with Runx2 to regulate osteoblast differentiation, including binding with activator protein 1 (AP-1) and activating transcription factor 4 (ATF4) which, with Runx2, regulate osteocalcin and osterix (Osx) $[13,14]$. Osx-deficient mice lack osteoblast formation, and Osx acts downstream of Runx2 $[13,14]$. In mouse systems, osteogenic factors stimulate osteogenesis through regulation of these transcription factors. BMP-2 promotes Runx 2 and Osx expression in murine osteoprogenitor and osteoblastic cells, and TGF- $\beta$ and FGF-2 may enhance osteoblast differentiation by increasing Runx 2 expression and activity $[13,14]$.

Wnt signaling plays a critical role in the regulation of osteoblast formation [19-23]. Canonical Wnt signaling pathway is activated by Wnt $1 / 3$ a that triggers phosphorylation of GSK3/Axin complex, leading to stabilization and nuclear translocation of the active dephosphorylated (dephospho) $\beta$-catenin, which in turn activates the lymphoid enhancer factor-1/T-cell factor transcription system [19-23]. BMP-2 and other osteogenic molecules induce osteoblastic differentiation of murine MSCs by stimulating Wnt signaling through modulation of Wnt stimulators and/or inhibitors [23]. Some reports show that BMP-2 inhibits Wnt signaling [24].

Several molecules negatively regulate canonical Wnt signaling by inducing phosphorylation and subsequent degradation of $\beta$-catenin, inhibiting osteoblast differentiation in murine osteoprogenitor cells. Dickkopfs (DKKs) including DKK-1 [25], the secreted frizzled-related proteins (sFRPs), such as sFRP-1, -2, -3, -4, and Wnt inhibitory factor-1 are the major soluble Wnt inhibitors present in murine osteoblasts, which block early osteoblast formation and induce the death of immature cells $[26,27]$. In vivo models support the role of canonical Wnt signaling in the regulation of bone formation 
[28-30]. Inactivating mutations of the LRP5 Wnt coreceptor cause osteoporosis, indicating that Wnt-mediated signaling via LRP5 affects bone accrual during growth and is important for the establishment of peak bone mass. Constitutive activating LRP5 mutations impair the action of normal antagonists of the Wnt pathway such as DKK-1 and increase Wnt signaling, which result in high bone density [29, 30]. Moreover, a targeted destruction of LRP5 in mice induces a low bone mass phenotype due to decrease of osteoblast proliferation and function independently to Runx 2 as demonstrated by a normal Runx2 expression in $\operatorname{Lrp} 5^{-/-}$mice [31]. On the other hand, it has been reported that canonical Wnt signaling promotes osteogenesis by directly stimulating Runx 2 gene expression [32]. In sFRP-1 null mice, which exhibit activated Wnt signaling and high bone mass phenotype, there is a significant increase of both T-cell factor and Runx2 expression [32]. Similarly, overexpression of the canonical activator Wnt10b in mice protects from bone loss of estrogen deficiency and shifts MSCs toward osteoblastic lineage by induction of Runx2 [33].

Despite the consistent findings between human genetic and mouse studies, which indicate that activation of canonical Wnt signaling stimulates bone formation, data obtained from human MSCs indicate that canonical Wnt activation by Wnt3a in human BM hMSCs suppresses osteogenic differentiation rather than stimulates osteoblastogenesis [3437]. These results suggest that Wnt signaling is required to maintain hMSCs in an undifferentiated state. It is likely that the effect of canonical Wnt signaling on osteogenesis in hMSCs depends on the level of Wnt activity given that hyperactivation of Wnt signaling by overexpressing LRP5 [29] can enhance osteogenesis, whereas exogenous levels of Wnt3a inhibit osteoblast differentiation $[34,35]$. On the other hand, the effect of canonical Wnt signaling may depend on the stage of differentiation of the cells. Accordingly, it has been reported that canonical Wnt signaling antagonizes the terminal steps of osteogenic differentiation as demonstrated by the evidence that mice lacking DKK-2 are osteopenic [38]. Consistently, an increased expression of Wnt antagonists during late osteoblast differentiation has been shown $[39,40]$.

Together with canonical Wnt signaling, a noncanonical Wnt pathway independent to the activation of $\beta$-catenin has been extensively demonstrated [19, 21, 41, 42]. Noncanonical Wnt signals are transduced through frizzled (FZD) receptor and Ror 2 coreceptor to several cascades involving disheveled or $\mathrm{Ca}^{++}$-dependent pathways. Rho family of small GTPase (RhoA, Rac) and JNK are downstream effectors of disheveled. Nemo-like kinase and the nuclear factor of activated T cells (NFATc1) are $\mathrm{Ca}^{++}$effectors of noncanonical pathways [41, 42]. Wnt-4, -5, and -11 proteins have been identified as specific activators of noncanonical Wnt pathway [41, 42]. Wnt5a is one of the most highly investigated noncanonical Wnt and is involved in almost all aspects of noncanonical Wnt signaling [43]. The noncanonical Wnts can trigger intracellular calcium flux, which can lead to the activation of calcium-dependent signaling molecules such as calmodulindependent protein kinase II (CAMKII) and protein kinase C
(PKC). In addition to FZD receptors, Wnt5a can also bind and activate the Ror2 receptor, resulting in the activation of the actin-binding protein filamin A and JNK signaling pathway. Wnt5a is also capable of inhibiting the activation of canonical signaling pathway by numerous mechanisms, either by calcium signaling through CAMKII or through Ror2 signaling pathway. In turn, this pathway can stimulate the TAK1-NLK pathway to phosphorylate and inactivate the active $\beta$-catenin transcription complex [43]. Recent evidence suggests that noncanonical Wnt pathway activation by Wnt5a blunts the inhibitory effect of Wnt3a on osteogenic differentiation of hMSCs and stimulates osteoblast differentiation [44, 45]. Similarly, noncanonical Wnt4 signaling enhances bone regeneration of hMSCs in vivo [44]. The proosteogenic effect of Wnt5a could be mediated by activation and homodimerization of the receptor Ror2 in hMSCs, whereas Wnt3a has no effect on Ror2 activation and homodimerization [45, 46]. It has been consistently shown that Ror 2 overexpression in hMSC induces expression of the osteogenic transcription factors Osx and Runx2 and induces osteogenic differentiation [46-48]. Finally, it has been recently demonstrated that noncanonical Wnt pathway through Nemo-like kinase represses peroxisome proliferation activated receptor- $\gamma$ transactivation and induces Runx2 expression promoting osteoblastogenesis in BM MSCs suggesting a potential relationship between noncanonical pathway and Runx2 activity [49]. This evidence indicates that noncanonical Wnt signaling has a critical role in the osteogenic differentiation process in hMSCs and that modulation of noncanonical Wnt signaling could be used to increase bone formation.

\section{Chondrogenic Differentiation of hMSCs}

Different MSC sources (BM, adipose tissue, synovial tissue, umbilical cord blood, periosteum, and synovial membrane) have been studied [50-52] to establish their chondrogenic potential, and BM and adipose tissue sources were the most studied for historical and easy accessibility reasons. Different parameters were considered and studied in hMSCs chondrogenic differentiation. In particular, hMSCs culture condition was one of the steps analyzed and was evidenced that hMSC expansion in vitro required FGF-2 to enhance the proliferative and chondrogenic potential $[53,54]$. Different studies demonstrated that the potential of hMSCs chondrogenic differentiation was enhanced using serum-free media [55], cells at passages between 3 and 6 [56], culture in three dimensions (i.e., micromasses) [57], incubator with lowoxygen tension $\left(2-5 \% \mathrm{O}_{2}\right)$ [58], and mechano stimulation [59].

Chondrogenic differentiation of BM hMSCs has been widely studied in vitro in micromass pellet condition that favors the induction of the first phase, characterized by cell condensation, as well as cell-cell and cell-extracellular matrix (ECM) interactions $[55,56]$. Subsequently, cells progress into a highly proliferative phase and start to produce typical components of the cartilaginous matrix (i.e., collagen type 2, collagen type 9, aggrecan, link protein, cartilage oligomeric matrix protein, and matrilin 1) [60-64]. Finally, cells become progressively rounded similar to chondroblast and 
then undergo hypertrophy expressing collagen type $\mathrm{X}$ and MMP13.

The different stages of chondrogenic differentiation are regulated by signaling factors like BMPs, FGF, TGF- $\beta$, Wnt, and Indian hedgehog (Ihh) that promote these processes. Different key transcription factors (SOX9, SOX5, SOX6, Slug, TRSP1, and GDF5) [65-68] have a crucial role in the control of stem cells properties as well as in the chondrogenic commitment status by driving the mesenchymal condensation and differentiation [65-67].

SOX9 is considered the master chondrogenic transcription factor since its expression is elevated in condensing mesenchymal progenitors $[69,70]$. SOX9 specifically interacts with two binding sites for HMG-domain proteins and activates elements in the promoters of Col2al, Col9al, Collla2, and aggrecan. Removal of SOX9 before mesenchymal condensation results in mice without cartilage development, while loss of SOX9 after condensation causes the arrest of chondrocytes differentiation [71]. SOX9 markedly inhibited activation of Wnt $/ \beta$-catenin-dependent promoters and stimulated degradation of $\beta$-catenin [72] by directing intracellular degradation, thus, favoring chondrocyte differentiation and delaying hypertrophic chondrocytes differentiation [69]. Studies performed on embryos in different stages of gestation evidenced that SOX9 and Runx2 control the transition from prehypertrophic to hypertrophic chondrocytes [73]. It has been demonstrated that upregulation of type $\mathrm{X}$ collagen (col10al), typical hypertrophic marker, is also regulated by overexpression of Wnt8c, Wnt9a and $\beta$-catenin that inhibited SOX9 and type II collagen (col2al) and induced Runx2 trascription factor [74]. SOX9 and Runx2 physically interact in MSC and while SOX9 can inhibit Runx2 transactivation, on the other hand, Runx2 exerts reciprocal inhibition on SOX9 transactivity [72]. These data provide convincing evidence that Runx2 induces chondrocyte hypertrophy. Rescue of Runx2 expression in mesenchymal condensation of Runx2-null mice restores chondrocytes hypertrophy without affecting osteogenesis [75].

SOX9 activates SOX5 and SOX6, and together they promote the early stage of differentiation when chondroblast proliferates and forms columnar chondrocytes and suppresses their terminal stage [76]. SOX5/SOX6 double-knockout mice show evidence of a severe, generalized chondrodysplasia indicating redundant functions of both transcriptor factors in chondrogenic differentiation [77]. SOX9 is not dependent on SOX5 and SOX6, and its level remains unaffected in mice with loss of SOX5 and SOX6. SOX5 and SOX6 have been suggested to potentiate transactivation of chondrocyte-specific gene SOX9 through cooperative binding to multiple recognition sites on enhancers [78]. SOX9, SOX5, and SOX6, often referred as SOX Trio, exert a cooperatively combined action to further upregulate the expression of type II, IX, and XI collagens and aggrecan [79]. Recent data have demonstrated that SOX5 and SOX6 proteins enhance miR-140 microRNA by promoting transactivation ability of SOX9 as homodimer, thus, providing new insights into cartilage-specific gene regulation by SOX trio [80].

\section{Potential Clinical Use of hMSCs for Bone and Cartilage Regeneration in Pediatric Orthopaedics}

The regenerative medicine approaches have been extensively studied to improve bone healing. Fracture nonunion and pseudarthrosis, defined as a false joint associated with abnormal movement at the site, are the prevalent bone pathology conditions where filling of the space with bone tissue is needed. However, in these conditions, bone supply is limited as well as autologous bone harvesting is accompanied with high rates of morbidity and allogeneic transplantation that inhere the risk of rejection [81]. Presently, hMSCs seem to be the most promising candidates for bone regeneration due to their osteogenic differentiation capacity [81].

The main rationale for the use of hMSCs in bone repair is based on the direct ability to generate osteoprogenitor cells by hMSCs further enhanced by the use of bone-stimulating agents such as BMP-2 also as genes delivered into hMSCs by viral or nonviral delivery systems [6]. However, more recent evidence suggests that the potential clinical effect of hMSCs is not only due to the direct conversion into osteoblasts, but also to an indirect one referred as paracrine effects supported by the production of several cytokines involved in osteoblastogenesis including bFGF, VEGF, PDGF, and TGF- $\beta$ [6]. In line with this hypothesis, it is possible that hMSCs can act to orchestrate the host response, increasing vascularization and host cell migration including osteoblastic cells.

The potential clinical use of hMSCs in fracture healing has been supposed by Hernigou et al. [82] who treated patients with atrophic nonunion of the tibia with percutaneous injection of concentrated BM. Others reported the use of scaffold loaded with expanded autologous hMSCs [83]. Scaffolds are used as carriers for expanded MSCs before bone implantation. Scaffolds mimic the natural environment of the bone matrix. The combined effect of scaffolds with growth factors has been shown to increase the formation and vascularization of bone [84-86]. Several scaffolds have been investigated in preclinical and clinical studies, although hydroxyapatite (HA) and calcium phosphate seem to be more useful because of their excellent osteoconductive properties [84-86]. HA provides good strength but is not resorbed, while beta-tricalcium phosphate $(\beta$-TCP) is fragile but has a greater capacity for resorption. Hence, a combination of HA and $\beta$-TCP, biphasic calcium phosphate, is generally used [84-86]. Moreover, HA can be combined with biodegradable polymer/bioceramic composites, including polylacticco-glycolic acid. Three-dimensional polymer scaffolds with dimensions of $150-500 \mu \mathrm{m}$ have been shown to have excellent stability and used for MSC therapy [84-86]. Expanded MSCs for three weeks and seeded them on macroporous HA scaffolds have been used to treat fracture nonunion [85].

Although the combination of growth factors and scaffolds remains a promising approach, genetic modification of MSCs to express growth or transcription factors, which involves either transfection of MSCs through viral vectors or by the use of nonviral vectors, is a suitable alternative. Viral vectors 
have been demonstrated to be a better delivery as compared to nonviral vectors for the higher efficiency in transfection and expression of the osteogenic factor [86, 87]. BMP-2transfected MSCs induce bone formation in mouse and in bony union of mouse radial defects. In another study, BMderived stem cells, which had been genetically modified with BMP4, were used to repair defects in the calvarial bone in rabbits [86, 87]. Moreover, permanent expression of BMP4 by retrovirus in BMSCs leads to regeneration of calvarial defects in rats $[86,87]$. Finally, overexpression of Runx2 has been demonstrated to stimulate osteoblast differentiation of engineered MSCs in mice [86, 87]. However, to date, any clinical studies have not applied ex vivo-expanded genetically modified MSCs because of the need to identify the optimal vector to ensure effective, safe, and consistent treatment.

Both autologous and allogeneic MSCs are potentially used for bone regeneration [88]. The use of allogeneic MSC for repair of large defects may be an alternative to autologous and allogeneic tissue-grafting procedures. Several authors have reported near equivalency when comparing allogeneic to autologous or syngeneic MSCs in healing models [88]. An allogeneic approach would enable MSC to be isolated from any donor, expanded and cryopreserved, providing a readily available source of progenitors for cell replacement therapy. Their immunomodulatory properties have raised the possibility of establishing allogeneic MSC banks for tissue regeneration. However, actually whether autologous or allogeneic MSCs should be preferred in the setting of regenerative medicine needs to be further investigated.

Congenital pseudarthrosis refers to a spontaneous fracture, which progresses to nonunion. In pediatrics, congenital pseudarthrosis is one of the most frustrating conditions encountered in orthopaedic surgery because of the difficulty in achieving healing. In fact, the most commonly used methods of treatment are the different modifications of Ilizarov technique, vascularized fibular grafting, bone grafting with intramedullary fixation, and Boyd's double-bone grafting. Finally, in case of bad results, significant shortening of the leg, even amputation, has to be considered. Numerous treatment options have been explored with varying levels of success $[89,90]$. Recently, a combined surgical technique using autologous BM hMSCs as adjuvant to the surgical stabilization by an external fixator or an intramedullary nailing was reported [91]. These combined techniques in tibia congenital pseudarthrosis were used in children with and without neurofibromatosis [91]. Neurofibromatosis type I (NF1) is one of the most common congenital diseases with a prevalence of one in 3000-4000 [92]. Neurofibromas, caféau-lait spots, and Lisch nodules are the hallmark of the disease [92]. However, NF1 is also characterized by several skeletal manifestations including congenital pseudarthrosis of the tibia. Bone alterations are likely to be related to a deficient osteoblast function with enhanced osteoclast activity and survival occurring in approximately $2-3 \%$ of children suffering from NF1. An impairment of osteogenic differentiation by MSCs has been demonstrated in NF1 [93, 94]. Mouse models lacking both alleles of NF1 specifically in limb osteochondroprogenitors (Nf1Prx model) and mature osteoblasts ( $\mathrm{NF} 1_{\mathrm{Ob}}{ }^{-/-}$model) displayed bone abnormalities that demonstrated the existence of a cell-autonomous role of NF1 in the mesenchymal lineage [95]. Defects in osteoblasts have also demonstrated that dysfunctions caused by loss of NF1 in osteoblasts impair callus maturation and weaken callus mechanical properties [96]. The most affected bone is the tibial diaphysis and dysplastic lesion having the radiological appearance of an anterior bowing, or a sclerotic lesion, or a fracture [97]. The congenital pseudarthrosis of the tibia (CPT) with/without NF1 is one of the most complex and disabling pediatric skeletal diseases. Congenital pseudarthrosis of the tibia appears to be caused by fibrous hamartoma originating from aberrant growth of NF1 haploinsufficient periosteal cells, which failed in terminal osteoblastic differentiation and was arrested at a certain stage of this process involving Runx2 and Wnt signaling [98]. Conservative treatment includes bracing of the affected limb continued until the end of skeletal growth. Surgical treatment includes several procedures, which are resection of the nonunion and reconstruction with either autologous nonvascularized bone grafting and intramedullary fixation or one-stage shortening followed by an Ilizarov external fixator to perform lengthening $[99,100]$. All these procedures have frequently unsatisfactory results because of the need for several operations for recalcitrant nonunion, residual deformity, and limb-length discrepancies [101]. Recently, the use of autologous hMSCs has garnered great interest, because their biological properties candidate them as a suitable source of osteogenic precursor for bone repair and regeneration, both in cell therapy and tissue engineering applications. Surgical treatment of pseudarthrotic lesions could benefit from regenerative medicine, which provides a biological approach to consolidation, based on the use of hMSCs and growth factors. These elements could lead to tissue healing and consolidation, in cases where traditional techniques fail. The biological bases of healing show that hMSCs transplantation derived from BM resident in iliac crest (IC) was able to differentiate into osteoblast with higher efficacy compared to resident in proximity of the pseudarthrosis site [91]. In our study, all the healing patients are $\mathrm{NF}^{+}$, and, in these patients, we found that osteogenic potential hMSCs derived from the iliac crest were more than those derived from the affected site [91]. Leskelä et al. [93] also confirmed these results. However, on the feasibility of this approach, any data are still not available on the osteogenic potential of MSC transplanted, because the microenvironment properties could also impair the successful procedure. Moreover, platelet-rich plasma (PRP) has been shown to stimulate osteoblast proliferation in vitro [102], probably due to the high levels of growth factors that can improve the BM hMSCs to form osteogenic and angiogenic tissue. The known growth factors include PDGF, TGF- $\beta 1$ and $\beta 2$, and IGF-1. Other growth factors present in PRP are VEGF and EGF [103].

In our study, 10 patients affected by refractory CPT were treated by using hMSCs derived from the iliac crest (ICMSCs), PRF, and lyophilized bone. In six patients, CPT was associated with NF1. Any complications related to marrow donor site were reported in this group of patients [91]. Bone consolidation was obtained in three patients who had CPT 
and NF1. In these patients, the IC-MSCs exposed to autologous serum were able to form mineral nodules in vitro, while the mineralizing ability was totally abrogated in patients with a poor clinical outcome [91]. Interestingly, we also reported that bFGF serum levels were significantly lower in patients who did not heal after surgery. The relationship between bFGF and bone healing was supported by in vitro experiments. In patients with poor clinical outcome, autologous serum was not sufficient to induce in vitro mineralization; however, it did occur when cells were cultured with bFGF [104]. The enhanced bone formation might indirectly depend on vascularization; in fact, the entirely healed patient had distal tibial pseudarthrosis. The distal tibia has naturally a better vascularization than the proximal site. An increased vascularization was also achieved by exogenous delivery of angiogenic growth factor by platelets, and hMSCs implant contributed to improve bone formation and consolidation. The improved vascularity might provide better nutrition and increase resorption and substitution by healthy tissue [105]. It is likely that this kind of therapy has a good clinical application because both components are autologous and easy to perform; it could reduce the healing time and the number of surgical treatments, especially in children, and the use of this combined technique may induce early bone healing and preserve the articular stiffness due to several surgical procedures and also reduce the leg's discrepancy that is due to the repetitive fractures. For all these evidences, it is reasonable to use this technique in patients treated with several operations before a demolitive surgery or a much more aggressive surgery like vascularized fibula. Figure 2 shows a representative patient with tibial pseudarthrosis healed after this type of combined treatment for three months.

Osteogenesis imperfecta (OI) is a genetic disorder of MSC due to mutations in the COL1A1 and COL1A2 genes characterized by production of defective type I collagen, generalized osteopenia that leads to bone deformities and fractures in children [106]. On the contrary, pseudarthrosis was not reported in this type of patients. Several pre-clinical studies in mouse indicate a role for cell therapy with MSCs in the treatment of OI $[84,85,107-110]$. Allogeneic BM transplantation has been reported in children suffering from severe OI and reported increased growth velocity, total body mineral content, and fewer fractures [108]. In a later study, isolated MSC from the original BM donors was gene marked and infused into six patients [109]. A low level of donor MSC was detected by PCR, and growth velocity was accelerated. The results, therefore, suggested the safety and feasibility of MSC therapy and a potential benefit to children with OI. Moreover, it has been reported that allogeneic HLAmismatched fetal liver MSCs uterus transplantation in a fetus with severe $\mathrm{OI}$ is capable of engrafting and differentiating into bone [110].

Cartilage is vulnerable to injury and has poor potential for repair. However, unlike bone, cartilage regeneration remains elusive. Procedures devoted to recruit stem cells from $\mathrm{BM}$ by penetration of the subchondral bone have been widely used to treat localized cartilage defects [111-113]. More recently, autologous chondrocyte implantation, alone or in combination with MSCs, has been introduced [111]. The use

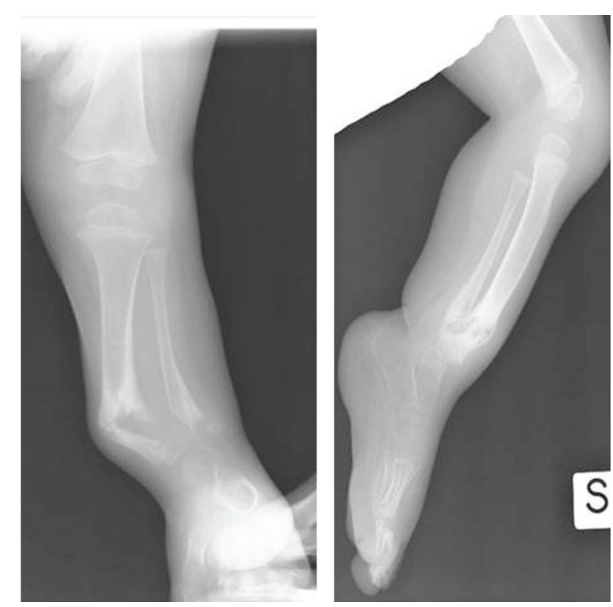

(a)

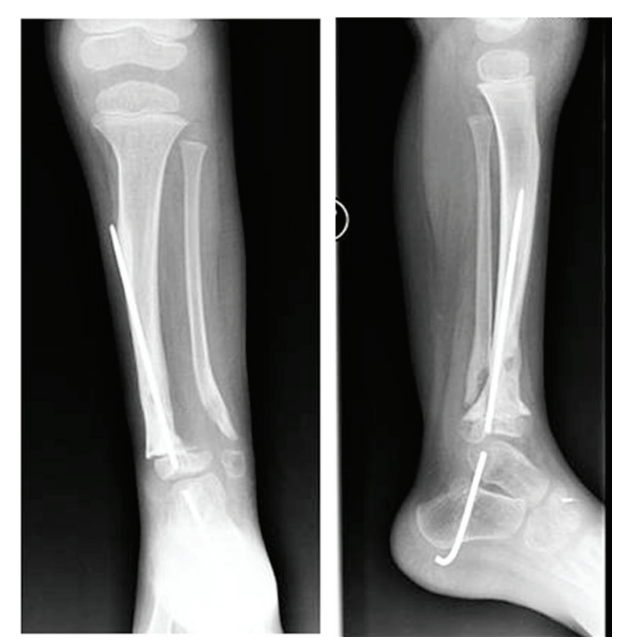

(b)

FIGURE 2: Clinical effect of the use of combined BM hMSC-based technique. Radiographics of a representative patient affected by NF1 with a tibial pseudarthrosis before (a) and three months (b) after the use of autologous BM hMSCs combined with platelet-rich fibrin and lyophilized bone.

of MSCs in cartilage regeneration includes microfracture, implantation, and recruitment from the synovial membrane $[112,113]$. However, all these applications are based on very small case series. The feasibility, efficacy, and safety of autologous MSC implantation for the treatment of cartilage defects were reported in osteochondral defect animal models demonstrating that MSCs transplanted into full-thickness cartilage defects recreate the layered arrangement of articular cartilage $[84,85,113]$. In human studies it has been reported that the patients that received autologous MSC therapy demonstrated substantial improvement in their symptoms, showing evidence of cartilage repair and the ability to resume their sporting and daily activities $[84,85,113]$. The progress of the patients was followed for up to 5 years, with no evidence of adverse effects from the MSC therapy $[84,85,113]$. The intraarticular injection of MSCs has been used to treat focal cartilage lesions or degenerative joint diseases in children. It has 
been recently published successful results, with no reported complication, of a 6-year follow-up study in four children injected intra-articularly with autologous BM-derived MSCs [114].

However, it still remains to be determined whether the resulting cartilage formation was attributed to the ex vivo expanded MSC directly or via an indirect paracrine mechanism which led to inhibition of inflammatory responses or by stimulating the growth and/or activity of endogenous progenitors and chondrocytes. MSCs can differentiate into chondrocytes and fibrochondrocytes resulting in a mixture of cartilaginous fibrous and hypertrophic tissues with only a short-term clinical success, because they do not possess functional mechanical properties [112]. By contrast, MSCs derived from synovial tissue have been shown to enhance chondrogenic potential and reduce the level of hypertrophic differentiation in comparison with MSCs derived from BM $[115,116]$, probably due to the development of articular cartilage during embryogenesis. Several issues have to be clarified in order to perform a successful cartilage regeneration such as appropriate cell sources and scaffold, creating biomechanically suitable tissues and integrating to native ones [112].

\section{Conclusions}

Osteogenic differentiation of hMSCs is tightly regulated by transcription factors that drive the type of tissue differentiation in hMSCs. The role of Runx2 and Wnt signaling has been elucidated in the past years both in vitro and in vivo, and growing evidence suggests that genetically modified MSC with these factors or with osteogenic factors such as BMP is useful to induce bone formation in pre-clinical models. The potential role of hMSCs in regenerative medicine is well known, and recent evidence suggests the potential use of hMSCs in bone regeneration in pediatric bone defects, particularly in the treatment of pseudarthrosis. Moreover, cell therapy for bone regeneration with lyophilized bone supplemented with platelet gel and BM hMSCs could be an adjuvant in the treatment of congenital pseudarthrosis of the tibial in pediatric orthopaedics. Further studies will be necessary to identify strategies for MSCs therapy for bone regeneration that take into account the characteristic of the tissue and permit to translate in a clinical setting the potential use of genetically modified MSCs.

\section{References}

[1] P. Bianco, X. Cao, P. S. Frenette et al., "The meaning, the sense and the significance: translating the science of mesenchymal stem cells into medicine," Nature Medicine, vol. 19, pp. 35-42, 2013.

[2] D. G. Phinney, "Functional heterogeneity of mesenchymal stem cells: implications for cell therapy," Journal of Cellular Biochemistry, vol. 113, pp. 2806-1282, 2012.

[3] M. Crisan, S. Yap, L. Casteilla et al., "A perivascular origin for mesenchymal stem cells in multiple human organs," Cell Stem Cell, vol. 3, no. 3, pp. 301-313, 2008.

[4] M. Corselli, C. W. Chen, M. Crisan, L. Lazzari, and B. Péault, "Perivascular ancestors of adult multipotent stem cells,"
Arteriosclerosis, Thrombosis, and Vascular Biology, vol. 30, no. 6, pp. 1104-1109, 2010.

[5] M. Dominici, K. Le Blanc, I. Mueller et al., "Minimal criteria for defining multipotent mesenchymal stromal cells. The International Society for Cellular Therapy position statement," Cytotherapy, vol. 8, no. 4, pp. 315-317, 2006.

[6] S. A. Boxall and E. Jones, "Markers for characterization of bone marrow multipotential stromal cells," Stem Cells International, vol. 2012, Article ID 975871, 12 pages, 2012.

[7] V. Rasini, M. Dominici, T. Kluba et al., "Mesenchymal stro$\mathrm{mal} / \mathrm{stem}$ cells markers in the human bone marrow," Cytotherapy, vol. 15, pp. 292-306, 2013.

[8] E. Jones and X. Yang, "Mesenchymal stem cells and bone regeneration: current status," Injury, vol. 42, no. 6, pp. 562-568, 2011.

[9] C. W. Chen, E. Montelatici, M. Crisan et al., "Perivascular multilineage progenitor cells in human organs: regenerative units, cytokine sources or both?" Cytokine and Growth Factor Reviews, vol. 20, no. 5-6, pp. 429-434, 2009.

[10] M. E. Bernardo, A. M. Cometa, D. Pagliara et al., "Ex vivo expansion of mesenchymal stromal cells," Best Practice \& Research Clinical Haematology, vol. 24, pp. 73-81, 2011.

[11] K. Le Blanc and W. Fibbe, "A new cell therapy registry coordinated by the European Group for Blood and Marrow Transplantation (EBMT)," Bone Marrow Transplantation, vol. 41, no. 3, p. 319, 2008.

[12] S. K. Kang, I. S. Shin, M. S. Ko et al., "Journey of mesenchymal stem cells for homing: strategies to enhance efficacy and safety of stem cell therapy," Stem Cells International, vol. 2012, Article ID 342968, 11 pages, 2012.

[13] Z. L. Deng, K. A. Sharff, N. Tang et al., "Regulation of osteogenic differentiation during skeletal development," Frontiers in Bioscience, vol. 13, no. 6, pp. 2001-2021, 2008.

[14] P. Ducy, R. Zhang, V. Geoffroy, A. L. Ridall, and G. Karsenty, "Osf2/Cbfal: a transcriptional activator of osteoblast differentiation," Cell, vol. 89, no. 5, pp. 747-754, 1997.

[15] W. Liu, S. Toyosawa, T. Furuichi et al., "Overexpression of Cbfal in osteoblasts inhibits osteoblast maturation and causes osteopenia with multiple fractures," Journal of Cell Biology, vol. 155, no. 1, pp. 157-166, 2001.

[16] V. Geoffroy, M. Kneissel, B. Fournier, A. Boyde, and P. Matthias, "High bone resorption in adult aging transgenic mice overexpressing Cbfal/Runx2 in cells of the osteoblastic lineage," Molecular and Cellular Biology, vol. 22, no. 17, pp. 6222-6233, 2002.

[17] C. Shui, T. C. Spelsberg, B. L. Riggs, and S. Khosla, "Changes in Runx2/Cbfal expression and activity during osteoblastic differentiation of human bone marrow stromal cells," Journal of Bone and Mineral Research, vol. 18, no. 2, pp. 213-221, 2003.

[18] G. Xiao, D. Jiang, P. Thomas et al., "MAPK pathways activate and phosphorylate the osteoblast-specific transcription factor, Cbfal," Journal of Biological Chemistry, vol. 275, no. 6, pp. 44534459, 2000.

[19] J. J. Westendorf, R. A. Kahler, and T. M. Schroeder, "Wnt signaling in osteoblasts and bone diseases," Gene, vol. 341, no. 1-2, pp. 19-39, 2004.

[20] V. Krishnan, H. U. Bryant, and O. A. MacDougald, "Regulation of bone mass by Wnt signaling," Journal of Clinical Investigation, vol. 116, no. 5, pp. 1202-1209, 2006.

[21] M. D. Gordon and R. Nusse, "Wnt signaling: multiple pathways, multiple receptors, and multiple transcription factors," Journal of Biological Chemistry, vol. 281, no. 32, pp. 22429-22433, 2006. 
[22] R. Baron and M. Kneissel, "WNT signaling in bone homeostasis and disease: from human mutations to treatments," Nature Medicine, vol. 19, no. 2, pp. 179-192, 2013.

[23] G. Rawadi, B. Vayssière, F. Dunn, R. Baron, and S. RomanRoman, "BMP-2 controls alkaline phosphatase expression and osteoblast mineralization by a Wnt autocrine loop," Journal of Bone and Mineral Research, vol. 18, no. 10, pp. 1842-1853, 2003.

[24] S. Minear, P. Leucht, S. Miller, and J. A. Helms, "rBMP represses Wnt signaling and influences skeletal progenitor cell fate specification during bone repair," Journal of Bone and Mineral Research, vol. 25, no. 6, pp. 1196-1207, 2010.

[25] A. Niida, T. Hiroko, M. Kasai et al., "DKK1, a negative regulator of Wnt signaling, is a target of the $\beta$-catenin/TCF pathway," Oncogene, vol. 23, no. 52, pp. 8520-8526, 2004.

[26] L. M. Galli, T. Barnes, T. Cheng et al., "Differential inhibition of Wnt-3a by Strp-1, Sfrp-2, and Sfrp-3," Developmental Dynamics, vol. 235, no. 3, pp. 681-690, 2006.

[27] J. Li, I. Sarosi, R. C. Cattley et al., "Dkk1-mediated inhibition of Wnt signaling in bone results in osteopenia," Bone, vol. 39, no. 4, pp. 754-766, 2006.

[28] L. M. Boyden, J. Mao, J. Belsky et al., "High bone density due to a mutation in LDL-receptor-related protein 5," New England Journal of Medicine, vol. 346, no. 20, pp. 1513-1521, 2002.

[29] Y. Gong, R. B. Slee, N. Fukai et al., "LDL receptor-related protein 5 (LRP5) affects bone accrual and eye development," Cell, vol. 107, no. 4, pp. 513-523, 2001.

[30] M. Ai, S. L. Holmen, W. van Hul, B. O. Williams, and M. L. Warman, "Reduced affinity to and inhibition by DKK1 form a common mechanism by which high bone mass-associated missense mutations in LRP5 affect canonical Wnt signaling," Molecular and Cellular Biology, vol. 25, no. 12, pp. 4946-4955, 2005.

[31] M. Kato, M. S. Patel, R. Levasseur et al., "Cbfal-independent decrease in osteoblast proliferation, osteopenia, and persistent embryonic eye vascularization in mice deficient in Lrp5, a Wnt coreceptor," Journal of Cell Biology, vol. 157, no. 2, pp. 303-314, 2002.

[32] T. Gaur, C. J. Lengner, H. Hovhannisyan et al., "Canonical WNT signaling promotes osteogenesis by directly stimulating Runx2 gene expression," Journal of Biological Chemistry, vol. 280, no. 39, pp. 33132-33140, 2005.

[33] C. N. Bennett, K. A. Longo, W. S. Wright et al., "Regulation of osteoblastogenesis and bone mass by Wnt10b," Proceedings of the National Academy of Sciences of the United States of America, vol. 102, no. 9, pp. 3324-3329, 2005.

[34] J. De Boer, R. Siddappa, C. Gaspar, A. van Apeldoorn, R. Fodde, and C. van Blitterswijk, "Wnt signaling inhibits osteogenic differentiation of human mesenchymal stem cells," Bone, vol. 34, no. 5, pp. 818-826, 2004.

[35] G. M. Boland, G. Perkins, D. J. Hall, and R. S. Tuan, "Wnt 3a promotes proliferation and suppresses osteogenic differentiation of adult human mesenchymal stem cells," Journal of Cellular Biochemistry, vol. 93, no. 6, pp. 1210-1230, 2004.

[36] D. Baksh, G. M. Boland, and R. S. Tuan, "Cross-talk between Wnt signaling pathways in human mesenchymal stem cells leads to functional antagonism during osteogenic differentiation," Journal of Cellular Biochemistry, vol. 101, no. 5, pp. 11091124, 2007.

[37] D. Baksh and R. S. Tuan, "Canonical and non-canonical Wnts differentially affect the development potential of primary isolate of human bone marrow mesenchymal stem cells," Journal of Cellular Physiology, vol. 212, no. 3, pp. 817-826, 2007.
[38] X. Li, P. Liu, W. Liu et al., "Dkk2 has a role in terminal osteoblast differentiation and mineralized matrix formation," Nature Genetics, vol. 37, no. 9, pp. 945-952, 2005.

[39] G. van der Horst, S. M. van der Werf, H. Farih-Sips, R. L. van Bezooijen, C. W. G. M. Löwik, and M. Karperien, "Downregulation of Wnt signaling by increased expression of Dickkopf-1 and -2 is a prerequisite for late-stage osteoblast differentiation of KS483 cells," Journal of Bone and Mineral Research, vol. 20, no. 10, pp. 1867-1877, 2005.

[40] B. L. T. Vaes, K. J. Dechering, E. P. van Someren et al., "Microarray analysis reveals expression regulation of Wnt antagonists in differentiating osteoblasts," Bone, vol. 36, no. 5, pp. 803-811, 2005.

[41] L. Ling, V. Nurcombe, and S. M. Cool, "Wnt signaling controls the fate of mesenchymal stem cells," Gene, vol. 433, no. 1-2, pp. $1-7,2009$.

[42] M. Katoh and M. Katoh, "WNT signaling pathway and stem cell signaling network," Clinical Cancer Research, vol. 13, no. 14, pp. 4042-4045, 2007.

[43] S. L. McDonald and A. Silver, "The opposing roles of Wnt-5a in cancer," British Journal of Cancer, vol. 101, no. 2, pp. 209-214, 2009.

[44] J. Chang, W. Sonoyama, Z. Wang et al., "Noncanonical Wnt4 signaling enhances bone regeneration of mesenchymal stem cells in craniofacial defects through activation of p38 MAPK," Journal of Biological Chemistry, vol. 282, no. 42, pp. 3093830948, 2007.

[45] Y. Liu, B. Rubin, P. V. N. Bodine, and J. Billiard, "Wnt5a induces homodimerization and activation of Ror2 receptor tyrosine kinase," Journal of Cellular Biochemistry, vol. 105, no. 2, pp. 497502, 2008.

[46] Y. Liu, J. F. Ross, P. V. N. Bodine, and J. Billiard, "Homodimerization of Ror2 tyrosine kinase receptor induces 14-3-3 $\beta$ phosphorylation and promotes osteoblast differentiation and bone formation," Molecular Endocrinology, vol. 21, no. 12, pp. 3050-3061, 2007.

[47] Y. Liu, R. A. Bhat, L. M. Seestaller-Wehr et al., "The orphan receptor tyrosine kinase Ror2 promotes osteoblast differentiation and enhances ex vivo bone formation," Molecular Endocrinology, vol. 21, no. 2, pp. 376-387, 2007.

[48] J. Billiard, D. S. Way, L. M. Seestaller-Wehr, R. A. Moran, A. Mangine, and P. V. N. Bodine, "The orphan receptor tyrosine kinase Ror2 modulates canonical Wnt signaling in osteoblastic cells," Molecular Endocrinology, vol. 19, no. 1, pp. 90-101, 2005.

[49] I. Takada, M. Mihara, M. Suzawa et al., "A histone lysine methyltransferase activated by non-canonical Wnt signalling suppresses PPAR- $\gamma$ transactivation," Nature Cell Biology, vol. 9, no. 11, pp. 1273-1285, 2007.

[50] D. Studer, C. Millan, E. Öztürk et al., "Molecular and biophysical mechanisms regulating hypertrophic differentiation in chondrocytes and mesenchymal stem cells," European Cells and Materials, vol. 24, pp. 118-135, 2012.

[51] B. Barrilleaux, D. G. Phinney, D. J. Prockop, and K. C. O'Connor, "Review: Ex vivo engineering of living tissues with adult stem cells," Tissue Engineering, vol. 12, no. 11, pp. 3007-3019, 2006.

[52] A. M. Freyria, S. Courtes, and F. Mallein-Gerin, "Differentiation of adult human mesenchymal stem cells: chondrogenic effect of BMP-2," Pathologie Biologie, vol. 56, no. 5, pp. 326-333, 2008.

[53] Y. Sakaguchi, I. Sekiya, K. Yagishita, and T. Muneta, "Comparison of human stem cells derived from various mesenchymal tissues: superiority of synovium as a cell source," Arthritis and Rheumatism, vol. 52, no. 8, pp. 2521-2529, 2005. 
[54] L. A. Solchaga, K. Penick, J. D. Porter, V. M. Goldberg, A. I. Caplan, and J. F. Welter, "FGF-2 enhances the mitotic and chondrogenic potentials of human adult bone marrow-derived mesenchymal stem cells," Journal of Cellular Physiology, vol. 203, no. 2, pp. 398-409, 2005.

[55] J. J. Auletta, E. A. Zale, J. F. Welter, and L. A. Solchaga, "Fibroblast growth factor-2 enhances expansion of human bone marrow-derived mesenchymal stromal cells without diminishing their immunosuppressive potential," Stem Cells International, vol. 2011, Article ID 235176, 10 pages, 2011.

[56] T. Felka, R. Schfer, P. De Zwart, and W. K. Aicher, "Animal serum-free expansion and differentiation of human mesenchymal stromal cells," Cytotherapy, vol. 12, no. 2, pp. 143-153, 2010.

[57] C. Cournil-Henrionnet, C. Huselstein, Y. Wang et al., "Phenotypic analysis of cell surface markers and gene expression of human mesenchymal stem cells and chondrocytes during monolayer expansion," Biorheology, vol. 45, no. 3-4, pp. 513-526, 2008.

[58] O. F. Gardner, C. W. Archer, M. Alini et al., "Chondrogenesis of mesenchymal stem cells for cartilage tissue engineering," Histology and Histopathology, vol. 28, pp. 23-42, 2013.

[59] A. B. Adesida, A. Mulet-Sierra, and N. M. Jomha, "Hypoxia mediated isolation and expansion enhances the chondrogenic capacity of bone marrow mesenchymal stromal cells," Stem Cell Research \& Therapy, vol. 3, no. 2, p. 9, 2012.

[60] R. Williams, I. M. Khan, K. Richardson et al., "Identification and clonal characterisation of a progenitor cell sub-population in normal human articular cartilage," PLoS ONE, vol. 5, no. 10, Article ID e13246, 2010.

[61] B. Grigolo, L. Roseti, M. Fiorini et al., "Transplantation of chondrocytes seeded on a hyaluronan derivative (Hyaff-11) into cartilage defects in rabbits," Biomaterials, vol. 22, no. 17, pp. 2417-2424, 2001.

[62] K. W. Kavalkovich, R. E. Boynton, J. M. Murphy et al., "Chondrogenic differentiation of human mesenchymal stem cells within an alginate layer culture system," In Vitro Cellular \& Developmental Biology, vol. 38, pp. 457-466, 2002.

[63] R. Tuli, W. J. Li, and R. S. Tuan, "Current state of cartilage tissue engineering," Arthritis Research and Therapy, vol. 5, no. 5, pp. 235-238, 2003.

[64] C. Karlsson, C. Brantsing, T. Svensson et al., "Differentiation of human mesenchymal stem cells and articular chondrocytes: analysis of chondrogenic potential and expression pattern of differentiation-related transcription factors," Journal of Orthopaedic Research, vol. 25, no. 2, pp. 152-163, 2007.

[65] K. G. A. Yang, D. B. F. Saris, R. E. Geuze et al., "Impact of expansion and redifferentiation conditions on chondrogenic capacity of cultured chondrocytes," Tissue Engineering, vol. 12, no. 9, pp. 2435-2447, 2006.

[66] S. Itoh, S. Kanno, Z. Gai et al., "Trps1 plays a pivotal role downstream of Gdf5 signaling in promoting chondrogenesis and apoptosis of ATDC5 cells," Genes to Cells, vol. 13, no. 4, pp. 355-363, 2008.

[67] V. Y. Leung, B. Gao, K. K. Leung et al., "SOX9 governs differentiation stage-specific gene expression in growth plate chondrocytes via direct concomitant transactivation and repression," PLoS Genet, vol. 7, Article ID e1002356, 2011.

[68] E. Torreggiani, G. Lisignoli, C. Manferdini et al., "Role of Slug transcription factor in human mesenchymal stem cells," Journal of Cellular and Molecular Medicine, vol. 16, pp. 740-751, 2012.

[69] H. Akiyama, J. P. Lyons, Y. Mori-Akiyama et al., "Interactions between Sox9 and $\beta$-catenin control chondrocyte differentiation," Genes and Development, vol. 18, no. 9, pp. 1072-1087, 2004.
[70] L. Quintana, N. I. Zur Nieden, and C. E. Semino, "Morphogenetic and regulatory mechanisms during developmental chondrogenesis: new paradigms for cartilage tissue engineering," Tissue Engineering B, vol. 15, no. 1, pp. 29-41, 2009.

[71] H. Akiyama, M. C. Chaboissier, J. F. Martin, A. Schedl, and B. De Crombrugghe, "The transcription factor Sox9 has essential roles in successive steps of the chondrocyte differentiation pathway and is required for expression of Sox 5 and Sox6," Genes and Development, vol. 16, no. 21, pp. 2813-2828, 2002.

[72] A. Cheng and P. G. Genever, "SOX9 determines RUNX2 transactivity by directing intracellular degradation," Journal of Bone and Mineral Research, vol. 25, no. 12, pp. 2680-2689, 2010.

[73] W. Bi, W. Huang, D. J. Whitworth et al., "Haploinsufficiency of Sox9 results in defective cartilage primordia and premature skeletal mineralization," Proceedings of the National Academy of Sciences of the United States of America, vol. 98, no. 12, pp. 66986703, 2001.

[74] Y. F. Dong, D. Y. Soung, E. M. Schwarz, R. J. O’Keefe, and H. Drissi, "Wnt induction of chondrocyte hypertrophy through the Runx2 transcription factor," Journal of Cellular Physiology, vol. 208, no. 1, pp. 77-86, 2006.

[75] S. Takeda, J. P. Bonnamy, M. J. Owen, P. Ducy, and G. Karsenty, "Continuous expression of Cbfal in nonhypertrophic chondrocytes uncovers its ability to induce hypertrophic chondrocyte differentiation and partially rescues Cbfal-deficient mice," Genes and Development, vol. 15, no. 4, pp. 467-481, 2001.

[76] T. Ikeda, S. Kamekura, A. Mabuchi et al., "The combination of SOX5, SOX6, and SOX9 (the SOX trio) provides signals sufficient for induction of permanent cartilage," Arthritis and Rheumatism, vol. 50, no. 11, pp. 3561-3573, 2004.

[77] P. Smits, P. Li, J. Mandel et al., "The transcription factors L-Sox5 and Sox6 are essential for cartilage formation," Developmental Cell, vol. 1, no. 2, pp. 277-290, 2001.

[78] Y. Han and V. Lefebvre, "L-Sox5 and Sox6 drive expression of the aggrecan gene in cartilage by securing binding of Sox 9 to a far-upstream enhancer," Molecular and Cellular Biology, vol. 28, no. 16, pp. 4999-5013, 2008.

[79] V. Lefebvre, R. R. Behringer, and B. De Crombrugghe, "LSox5, Sox6 and SOx9 control essential steps of the chondrocyte differentiation pathway," Osteoarthritis and Cartilage, vol. 9, supplement A, pp. S69-S75, 2001.

[80] S. Yamashita, S. Miyaki, Y. Kato et al., "L-Sox5 and Sox6 proteins enhance chondrogenic miR-140 microRNA expression by strengthening dimeric Sox9 activity," Journal of Biological Chemistry, vol. 287, pp. 22206-22215, 2012.

[81] S. Beyth, J. Schroeder, and M. Liebergall, "Stem cells in bone diseases: current clinical practice," British Medical Bulletin, vol. 99, pp. 199-210, 2011.

[82] P. Hernigou, A. Poignard, F. Beaujean, and H. Rouard, "Percutaneous autologous bone-marrow grafting for nonunions: influence of the number and concentration of progenitor cells," Journal of Bone and Joint Surgery A, vol. 87, no. 7, pp. 1430-1437, 2005.

[83] R. Quarto, M. Mastrogiacomo, R. Cancedda et al., "Repair of large bone defects with the use of autologous bone marrow stromal cells," New England Journal of Medicine, vol. 344, no. 5, pp. 385-386, 2001.

[84] A. Arthur, A. Zannettino, and S. Gronthos, "The therapeutic applications of multipotential mesenchymal/stromal stem cells in skeletal tissue repair," Journal of Cellular Physiology, vol. 218, no. 2, pp. 237-245, 2009.

[85] G. A. Norambuena, M. Khoury, and C. Jorgensen, "Mesenchymal stem cells in osteoarticular pediatric diseases: an update," Pediatric Research, vol. 71, no. 4, Part 2, pp. 452-458, 2012. 
[86] N. K. Satija, V. K. Singh, Y. K. Verma et al., "Mesenchymal stem cell-based therapy: a new paradigm in regenerative medicine," Journal of Cellular and Molecular Medicine, vol. 13, no. 11-12, pp. 4385-4402, 2009.

[87] T. Meyerrose, S. Olson, S. Pontow et al., "Mesenchymal stem cells for the sustained in vivo delivery of bioactive factors," Advanced Drug Delivery Reviews, vol. 62, no. 12, pp. 1167-1174, 2010.

[88] M. E. Bernardo, D. Pagliara, and F. Locatelli, "Mesenchymal stromal cell therapy: a revolution in Regenerative Medicine?" Bone Marrow Transplant, vol. 47, pp. 164-171, 2012.

[89] C. E. Johnston II, "Congenital pseudarthrosis of the tibia. Results of technical variations in the Charnley-Williams procedure," Journal of Bone and Joint Surgery A, vol. 84, no. 10, pp. 1799-1810, 2002.

[90] S. Boero, M. Catagni, O. Donzelli, R. Facchini, and P. V. Frediani, "Congenital pseudarthrosis of the tibia associated with neurofibromatosis-1: treatment with Ilizarov's device," Journal of Pediatric Orthopaedics, vol. 17, no. 5, pp. 675-684, 1997.

[91] D. Granchi, V. Devescovi, S. R. Baglio, M. Magnani, O. Donzelli, and N. Baldini, "A regenerative approach for bone repair in congenital pseudarthrosis of the tibia associated or not associated with type 1 neurofibromatosis: correlation between laboratory findings and clinical outcome," Cytotherapy, vol.14, pp. 306-314, 2012.

[92] E. Pasmant, M. Vidaud, D. Vidaud, and P. Wolkenstein, "Neurofibromatosis type 1: from genotype to phenotype," Journal of Medical Genetics, vol. 49, pp. 483-489, 2012.

[93] H. V. Leskelä, T. Kuorilehto, J. Risteli et al., "Congenital pseudarthrosis of neurofibromatosis type 1: impaired osteoblast differentiation and function and altered NF1 gene expression," Bone, vol. 44, no. 2, pp. 243-250, 2009.

[94] X. Wu, S. A. Estwick, S. Chen et al., "Neurofibromin plays a critical role in modulating osteoblast differentiation of mesenchymal stem/progenitor cells," Human Molecular Genetics, vol. 15, no. 19, pp. 2837-2845, 2006.

[95] W. Wang, J. S. Nyman, K. Ono et al., "Mice lacking Nf1 in osteochondroprogenitor cells display skeletal dysplasia similar to patients with neurofibromatosis type I," Human Molecular Genetics, vol. 20, pp. 3910-3924, 2011.

[96] W. Wang, J. S. Nyman, H. E. Moss et al., "Local low-dose lovastatin delivery improves the bone-healing defect caused by Nf1 loss of function in osteoblasts," Journal of Bone and Mineral Research, vol. 25, no. 7, pp. 1658-1667, 2010.

[97] D. S. Feldman, C. Jordan, and L. Fonseca, "Orthopaedic manifestations of neurofibromatosis type 1," Journal of the American Academy of Orthopaedic Surgeons, vol. 18, no. 6, pp. 346-357, 2010.

[98] D. Y. Lee, T. J. Cho, H. R. Lee et al., "Disturbed osteoblastic differentiation of fibrous hamartoma cell from congenital pseudarthrosis of the tibia associated with neurofibromatosis type I," Clinics in Orthopedic Surgery, vol. 3, pp. 230-237, 2011.

[99] C. E. Johnston and J. G. Birch, "A tale of two tibias: a review of treatment options for congenital pseudarthrosis of the tibia," Journal of Children's Orthopaedics, vol. 2, no. 2, pp. 133-149, 2008.

[100] D. Erni, S. De Kerviler, R. Hertel, and T. Slongo, "Vascularised fibula grafts for early tibia reconstruction in infants with congenital pseudarthrosis," Journal of Plastic, Reconstructive and Aesthetic Surgery, vol. 63, no. 10, pp. 1699-1704, 2010.

[101] J. P. Krüger, S. Hondke, M. Endres, A. Pruss, A. Siclari, and C. Kaps, "Human platelet-rich plasma stimulates migration and chondrogenic differentiation of human subchondral progenitor cells," Journal of Orthopaedic Research, vol. 30, pp. 845-852, 2012.
[102] H. Kitoh, T. Kitakoji, H. Tsuchiya et al., "Transplantation of marrow-derived mesenchymal stem cells and platelet-rich plasma during distraction osteogenesis-a preliminary result of three cases," Bone, vol. 35, no. 4, pp. 892-898, 2004.

[103] M. Wrotniak, T. Bielecki, and T. S. Gaździk, "Current opinion about using the platelet-rich gel in orthopaedics and trauma surgery," Ortopedia Traumatologia Rehabilitacja, vol. 9, no. 3, pp. 227-238, 2007.

[104] D. Granchi, V. Devescovi, L. Pratelli et al., "Serum levels of fibroblast growth factor 2 in children with orthopedic diseases: potential role in predicting bone healing," Journal of Orthopaedic Research, vol. 31, pp. 249-556, 2013.

[105] U. G. Longo, U. Trovato, M. Loppini et al., "Tissue engineered strategies for pseudoarthrosis," Open Orthopaedics Journal, vol. 6, pp. 564-570, 2012.

[106] T. Cundy, "Recent advances in osteogenesis imperfecta," Calcified Tissue International, vol. 90, pp. 439-449, 2012.

[107] I. Pelagiadis, H. Dimitriou, and M. Kalmanti, "Biologic characteristics of mesenchymal stromal cells and their clinical applications in pediatric patients," Journal of Pediatric Hematology/Oncology, vol. 30, no. 4, pp. 301-309, 2008.

[108] E. M. Horwitz, D. J. Prockop, L. A. Fitzpatrick et al., "Transplantability and therapeutic effects of bone marrow-derived mesenchymal cells in children with osteogenesis imperfecta," Nature Medicine, vol. 5, no. 3, pp. 309-313, 1999.

[109] E. M. Horwitz, D. J. Prockop, P. L. Gordon et al., "Clinical responses to bone marrow transplantation in children with severe osteogenesis imperfecta," Blood, vol. 97, no. 5, pp. 12271231, 2001.

[110] K. Le Blanc, C. Götherström, O. Ringdén et al., "Fetal mesenchymal stem-cell engraftment in bone after in utero transplantation in a patient with severe osteogenesis imperfecta," Transplantation, vol. 79, pp. 1607-1614, 2005.

[111] E. H. Lee and J. H. P. Hui, "The potential of stem cells in orthopaedic surgery," Journal of Bone and Joint Surgery B, vol. 88, no. 7, pp. 841-851, 2006.

[112] D. J. Huey, J. C. Hu, and K. A. Athanasiou, "Unlike bone, cartilage regeneration remains elusive," Science, vol. 338, pp. 917-921, 2012.

[113] A. Schmitt, M. van Griensven, A. B. Imhoff et al., "Application of stem cells in orthopedics," Stem Cells International, vol. 2012, Article ID 394962, 11 pages, 2012.

[114] S. Wakitani, T. Okabe, S. Horibe et al., "Safety of autologous bone marrow-derived mesenchymal stem cell transplantation for cartilage repair in 41 patients with 45 joints followed for up to 11 years and 5 months," Journal of Tissue Engineering and Regenerative Medicine, vol. 5, no. 2, pp. 146-150, 2011.

[115] M. Pei, F. He, and G. Vunjak-Novakovic, "Synovium-derived stem cell-based chondrogenesis," Differentiation, vol. 76, no. 10, pp. 1044-1056, 2008.

[116] M. Pei, D. Chen, J. Li, and L. Wei, "Histone deacetylase 4 promotes TGF- $\beta 1$-induced synovium-derived stem cell chondrogenesis but inhibits chondrogenically differentiated stem cell hypertrophy," Differentiation, vol. 78, no. 5, pp. 260-268, 2009. 

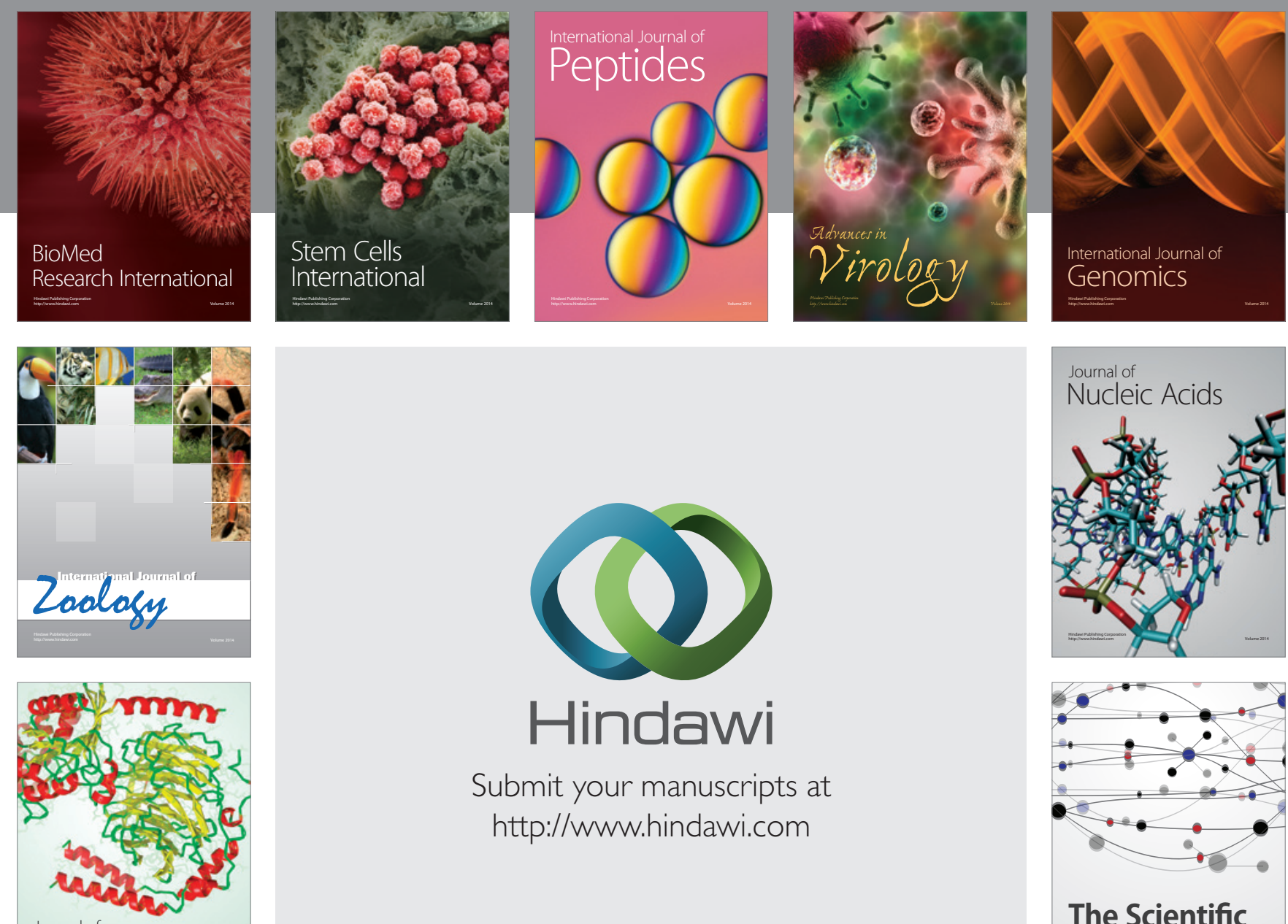

Submit your manuscripts at

http://www.hindawi.com

Journal of
Signal Transduction
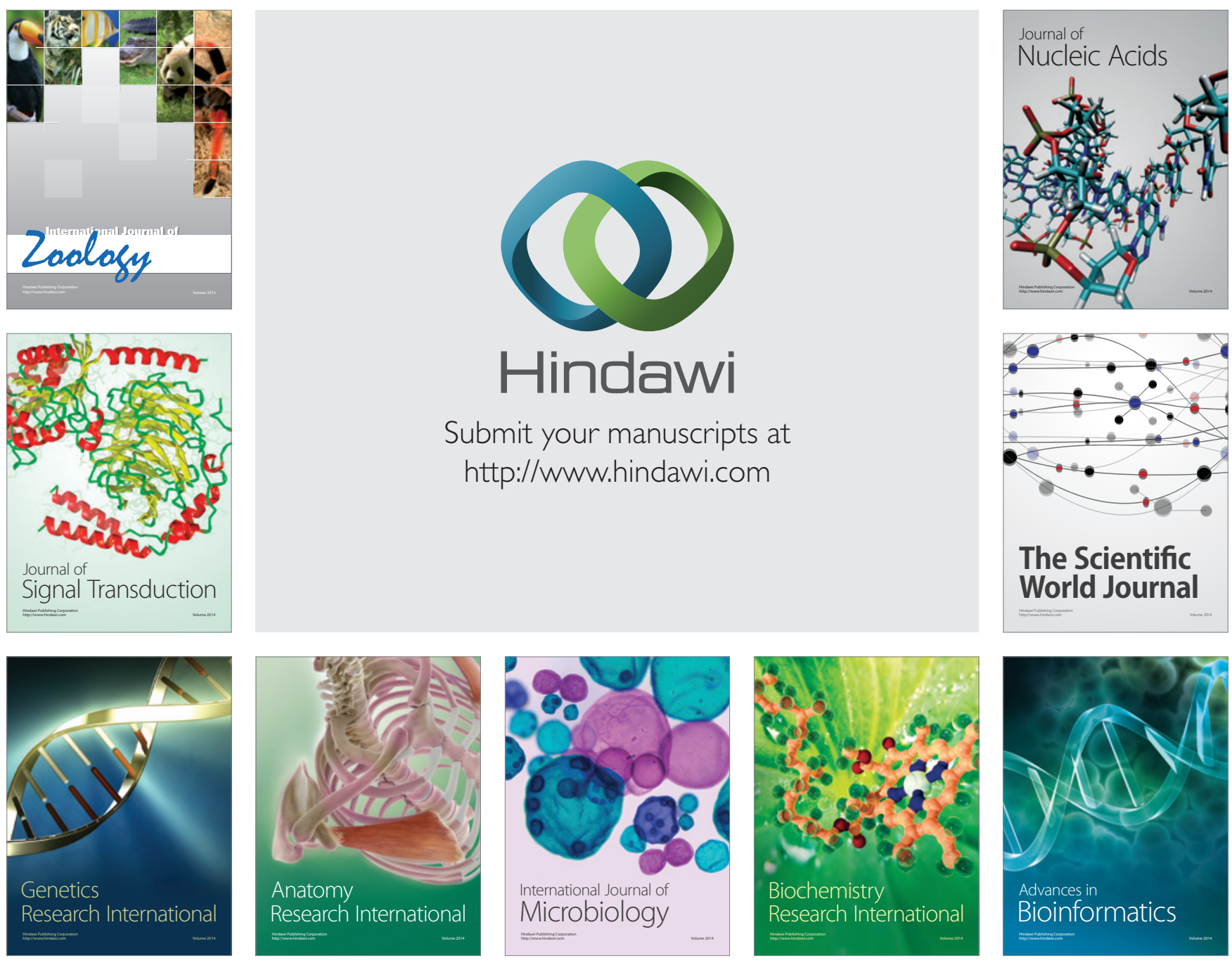

The Scientific World Journal
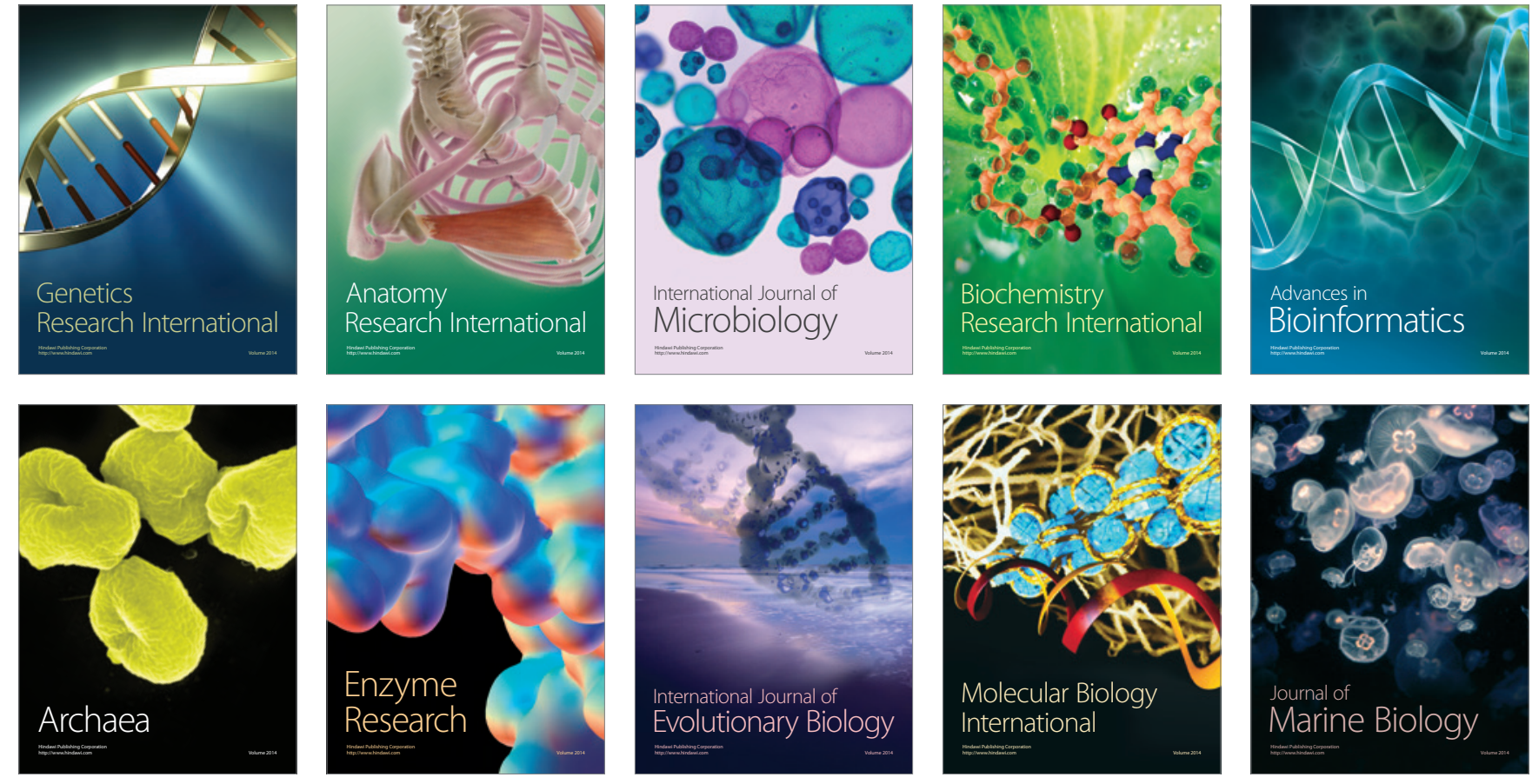